University of Wollongong

Research Online

Faculty of Social Sciences - Papers (Archive) Faculty of Arts, Social Sciences \& Humanities

$1-1-2019$

Effects of postural stability, active control, exposure duration and repeated exposures on HMD induced cybersickness

Dante Risi

University of Wollongong

Stephen Palmisano

University of Wollongong, stephenp@uow.edu.au

Follow this and additional works at: https://ro.uow.edu.au/sspapers

Part of the Education Commons, and the Social and Behavioral Sciences Commons

Research Online is the open access institutional repository for the University of Wollongong. For further information contact the UOW Library: research-pubs@uow.edu.au 


\title{
Effects of postural stability, active control, exposure duration and repeated exposures on HMD induced cybersickness
}

\begin{abstract}
Cybersickness is common during head-mounted display (HMD) based virtual reality. This study examined whether it is possible to: (1) identify people who are more susceptible to this cybersickness; and (2) find general ways to reduce its occurrence and severity. Our participants were exposed to HMD-based virtual reality four times over two different days (using "Freedom Locomotion VR"). During these 10-min trials, participants were either free-standing or posturally restrained as they actively controlled or passively viewed their locomotion through the virtual environment. Cybersickness was found to increase steadily over time during each exposure. While this cybersickness was markedly reduced on day 2 (compared to day 1), it was not significantly altered by either the use of postural restraints or active locomotion control. However, the sick and well participants in our study were found to differ in terms of their spontaneous postural activity (before they entered virtual reality). We found that the participants who experienced stronger vection also tended to report more severe cybersickness in this study. These findings suggest that we should be able to identify people who are more susceptible to cybersickness and help them become more resistant to it (via repeated exposures to HMD-based virtual reality).

\section{Disciplines}

Education | Social and Behavioral Sciences

\section{Publication Details}

Risi, D. \& Palmisano, S. (2019). Effects of postural stability, active control, exposure duration and repeated exposures on HMD induced cybersickness. Displays, 60 9-17.
\end{abstract}


Effects of Postural Stability, Active Control, Exposure Duration and Repeated Exposures on HMD induced Cybersickness

\author{
Dante Risi ${ }^{1} \&$ Stephen Palmisano ${ }^{1 *}$ \\ ${ }^{1}$ School of Psychology, University of Wollongong, NSW, 2522, Australia.
}

*Corresponding author:

Stephen Palmisano,

Email: stephenp@uow.edu.au

Short title: Effects on HMD induced Cybersickness

Keywords: motion sickness; cybersickness; virtual reality; head-mounted display; vection. 


\section{ABSTRACT}

Cybersickness is common during head-mounted display (HMD) based virtual reality. This study examined whether it is possible to: 1 ) identify people who are more susceptible to this cybersickness; and 2) find general ways to reduce its occurrence and severity. Our participants were exposed to HMD-based virtual reality four times over two different days (using "Freedom Locomotion VR"). During these 10-minute trials, participants were either free-standing or posturally restrained as they actively controlled or passively viewed their locomotion through the virtual environment. Cybersickness was found to increase steadily over time during each exposure. While this cybersickness was markedly reduced on day 2 (compared to day 1), it was not significantly altered by either the use of postural restraints or active locomotion control. However, the sick and well participants in our study were found to differ in terms of their spontaneous postural activity (before they entered virtual reality). We also found that the participants who experienced stronger vection also tended to report more severe cybersickness in this study. These findings suggest that we should be able to identify people who are more susceptible to cybersickness and help them become more resistant to it (via repeated exposures to HMD-based virtual reality). 


\section{INTRODUCTION}

Modern head-mounted displays (HMDs), such as the Oculus Rift, HTC Vive and Play Station VR, are bringing immersive virtual reality-based gaming and entertainment into our homes. HMDs are now also being utilized in a wide array of vocational fields, including medicine $[1,2]$, clinical psychology/psychiatry [3], defense [4], aerospace [5], and education [6]. However, the spread of this technology continues to be hindered by the cybersickness that HMDs often produce - including disorientation, oculomotor and nausea symptoms [7]. In principle, the provocative stimulation for this type of sickness could be visual, non-visual or even multisensory in active HMD users [7-10]. This cybersickness also appears to be more common, and tends to be more severe, than the visually-induced motion sickness produced by desktop screens and large projection displays $[7,11]$. Studies have reported that this cybersickness can occur for up to $80 \%$ of users and symptoms can persist for up to 12 hours after exposure $[7,10,12,13]$.

\subsection{Explanations of Cybersickness}

Over the years motion sickness has been variously attributed to sensory conflict $[14,15]$, postural instability [16], particular types of eye-movements [17] and even misperceptions of poisoning [18]. While it is possible that all of these factors contribute to motion sickness, here we will focus on the two most widely cited explanations of cybersickness (sensory conflict and postural instability).

According to sensory conflict theories, motion sickness occurs when signals from our visual and non-visual senses disagree either with each other or with what is expected based on past experience $[14,15,19,20]$. In the specific case of HMD-based virtual reality, users often experience compelling visual illusions of self-motion, known as vection [21-23]. It is widely believed that this vection plays a causal role in cybersickness $[24,25]$. Because the vestibular stimulation that would normally accompany the visual self-motion stimulation is absent, this vection is thought to generate sensory conflicts in HMD users [26-30]. However, the empirical support for this vection-based explanation of cybersickness is mixed (see [27] for a review). While some studies have reported significant positive correlations between vection and visually induced motion sickness [31-37], others have failed to find support for 
the proposal [38-45] - reporting either non-significant or negative relationships between them.

Postural instability provides another popular explanation of cybersickness [16]. Postural instability theory assumes that postural instability (not vection) is responsible for generating all types of motion sickness. Consistent with this theory, studies have shown that: 1) people who are more naturally unstable are also more likely to become sick when exposed to visual motion; and 2) the onset of this visually-induced motion sickness is preceded by changes in postural stability [46-59]. While the motion stimulation in these past studies was provided by large moving rooms, handheld devices and console video games, a few newer studies have also tested the predictions of postural instability theory on the cybersickness produced by HMDs. Arcioni et al. [8] and Munafo et al. [60] both found that naturally unstable participants were more likely to become sick when exposed to HMD-based virtual reality. Similarly, Merhi et al. [61] reported that postural activity changed just prior to their participants' first reports of cybersickness. While their findings are promising, these studies all used older HMDs (either the Oculus Rift DK1/DK2 or a Visette pro) and only some of them had head-tracking enabled. Therefore further testing is required to confirm these findings with the next generation of HMDs and under more interactive conditions.

\subsection{The Current Study}

Evidence suggests that individual differences in postural stability can be used to predict who will become sick (and who will remain well) when exposed to HMD-based virtual reality $[8,60]$. The current study re-examined this relationship using the more advanced Oculus Rift CV1 HMD. Postural stability in this, and the past, studies was: 1) assumed to be an enduring characteristic of the participant; and 2) estimated based on fluctuations in his/her center of foot pressure (COP) before exposure to HMD-based virtual reality. However, as COP timeseries data are typically complex and non-stationary, we obtained multiple samples of spontaneous postural activity for each participant in this study (with 4 eyes-open and 1 eyesclosed COP recordings made before each of their 4 exposures to HMD-based virtual reality).

We also planned to examine both the positional variability and the temporal dynamics of this COP data.

However, the current study was not only focused on predicting who would be more likely to become sick during HMD-based virtual reality (based on their spontaneous postural 
activity). It also examined the effectiveness of various methods/techniques of reducing cybersickness. Based on a review of the literature, we identified three possible methods for reducing cybersickness in the current study, which are discussed in the sections below.

\subsubsection{The Use of Postural Restraints}

Passive postural restraints, such as seat belts in cars or safety restraints on rollercoasters, restrict bodily movements and increase postural stability [47]. Thus it has been proposed that they should also reduce the cybersickness produced by HMDs (compared to free-standing conditions). Consistent with this notion, passive postural restraints have been shown to reduce the motion sickness experienced during console-based motorcycle and car racing videogames $[47,62]$. Related research has also shown that cybersickness is more common when HMD users are standing as opposed to seated [61]. However, not all studies support this proposal. For example, Faugloire et al. [50] found that passive postural restraints did not reduce the motion sickness from a large swinging room (although they did find that postural activity measured during passive restraint differed between their sick and well participants). The proposal that postural restraints might reduce motion sickness is further complicated by Bonnet et al.'s [63] finding that motion sickness could still be reported during passive restraint in the absence of any imposed motion. To the best of our knowledge, the current study will be the first to examine whether the use of postural restraints can reduce the cybersickness induced by HMD-based virtual reality.

\subsubsection{Active Control Over the Simulation}

HMD-based virtual reality experiences range from passive viewing (e.g., looking at video content and roller coaster rides) to highly interactive videogames where the user not only looks around, but also actively controls their virtual locomotion. It is well known that automobile drivers are less likely to become sick than their passengers in the real world. Recent studies have demonstrated that this advantage also generalizes to console-based video games. In their study, Dong et al. [64] reported that 'passengers' (who only watched a console driving game) were significantly more likely to report motion sickness than the 'drivers' (who actively controlled the game). Chen et al. [65] demonstrated that this effect was not restricted to (real/simulated) vehicular control. They found that 'watchers' of firstperson locomotion in a shooter game were more likely to become sick than those who actively 
controlled the game play. In the current study we will compare the cybersickness induced when users are actively controlling and passively viewing their HMD-based experiences of virtual reality.

\subsubsection{Repeated Exposures to HMD-based Virtual Reality}

The likelihood and severity of cybersickness generally decreases with repeated exposures to HMD-based virtual reality [26,66-69]. Regan [69] reported that her participants experienced considerably less cybersickness on their second exposure to HMD-based virtual reality (even though there was $\sim 4$ months between each of their 20-minute exposures). Hill and Howarth [26] also found that cybersickness decreased with repeated 20-minute exposures to the same game over five consecutive days. Howarth and Hodder [66] later replicated and extended these findings. They found that reductions in the cybersickness produced by 10 repeated exposures to HMD-based virtual reality were similar for all of the inter-trial intervals that they tested (i.e., from 1 to 7 days). More recently, Gavgani et al. [66] found that repeated 15-minute exposures over 3 consecutive days produced significant reductions in both subjective and physiological measures of cybersickness. While we also expect cybersickness to decrease with repeated exposures in the current study, it should be noted that the HMDs in the above studies: 1) were often old (e.g., Oculus Rift DK1 or earlier), 2) did not have head tracking enabled in most cases; and 3) typically presented nonstereoscopic displays. The current study will therefore further investigate reports that cybersickness is markedly reduced by the second exposure to HMD-based virtual reality (see also [62] and [70] for additional evidence of day 1 versus day 2 effects in non-HMD based driving simulator studies). We will also determine whether such reductions are possible with shorter individual exposure durations (i.e., 10-, as opposed to 15- or 20-, minutes) and when the repeats are provided on the same, as well as different, days. 


\section{MATERIALS AND METHODS}

\subsection{Participants}

15 male and 5 female adult participants (mean age of 26.5 years; Standard deviation 6.9 years) were recruited from the University of Wollongong and the general population. These participants all had normal or corrected-to-normal vision and no self-reported visual, vestibular, or neurological impairments. All reported feeling well at the start of the experiment. The study was approved in advance by the UOW Ethics Committee and each participant provided informed written consent prior to participating.

\subsection{Materials}

The virtual reality software used in this study was "Freedom Locomotion VR" (https://hugerobotvr.com/projects/) downloaded from the Steam Store ${ }^{\mathrm{TM}}$. It was run on a high-performance Microsoft Windows 8 desktop computer (with an Intel 6th generation CPU and an NVidia GeForce GTX980Ti graphics card) and actively viewed using an Oculus Rift CV1 $\mathrm{HMD}$ (with a binocular field of view of $110^{\circ}$ diagonal, as well as a resolution of $1,080 \times 1,200$ per eye and a refresh rate of $90 \mathrm{~Hz}$ ). The course selected was "Futuristic Rooftop" and the gameplay was set to "no-comfort mode" (so there was no reduction in the user's field of view during simulated self-motion). The virtual locomotion method ("sliding locomotion") allowed the participant or the experimenter to control their simulated self-motion using the Oculus Touch hand remotes. Their simulated self-motions were generated by moving the joystick on these hand remotes - this briefly accelerated the user up from 0 to $10 \mathrm{~km} / \mathrm{h}$ (the constant set speed of locomotion). Snap turns could also be made by holding the " $X$ " or " $Y$ " buttons and then rotating one of the hand remotes in yaw until the desired point of view was reached. This allowed the participant to stand still and in place throughout each simulation. Cybersickness symptoms and severity were measured using Simulator Sickness Questionnaire (SSQ) [71] and Fast Motion Sickness (FMS) Scale [72]. Postural activity was also measured using a Bertec balance plate (http://bertec.com/products/balance-plates.html). A ceiling mounted safety harness (https://www.beaver.com.au/fall-prevention/bodyharnesses/harness-b-safe-black-and-old-c-w-side- $d$-s) was also used to support the participant during the postural restraint conditions.

\subsection{Design}


Each participant was tested with four trials run over two consecutive days. The two testing sessions were separated by at least 12 hours (in order to limit any residual motion sickness effects from the first day's testing session). Each testing session consisted of two trials. Before donning the HMD at the start of each of these trials, the participants were first checked for any sickness symptoms and then they had their postural stability assessed on the balance plate with their eyes open and eyes closed. The experiment itself had a 2 (SUPPORT TYPE) x 2 (CONTROL TYPE) X 5 (TIME IN TRIAL) within-subjects design. Postural restraint was always provided on one of the two testing days, and participants were always free-standing on the other testing day. On both days, the participants were first exposed to a passive viewing trial (where the researcher controlled their simulated self-motion), and then participants were next given an active control trial (where they had to follow the same predetermined course through the virtual environment shown to them on the first trial). During each 10-minute exposure to virtual reality, participants rated the severity of their cybersickness every 2 minutes. Then directly after each of these exposures they had to: 1 ) rate the vection for that trial; 2 ) indicate whether or not the trial had made them feel sick; and 3) rate any current sickness symptoms.

\subsection{Procedure}

Participants were initially provided with a brief description of the experiment (along with definitions of the key terms). Then their height, weight and foot size were measured. Participants also had their postural stability assessed before each of the four experimental trials. They were asked to stand quietly on the Bertec balance plate while the fluctuations in their center of foot pressure (COP) were recorded for $60 \mathrm{~s}$ periods. In each of these assessments, participants had their eyes open for the first four COP recordings and then closed for the final COP recording. There was always a $60 \mathrm{~s}$ interval between each of these recordings (during which time participants stepped off the balance plate and were instructed to relax).

Participants next completed the pre-exposure items of the SSQ. Prior to their postural restraint trials, they were helped into the safety harness by the researcher and instructed to lean forward slightly until they felt fully supported. Before active control trials, participants were also briefly familiarized with the Oculus Touch controllers. Participants next donned their HMDs and began their 10-minute exposure to Freedom Locomotion VR. During passive 
viewing trials, the researcher controlled their virtual locomotion along the pre-determined course. By contrast, during active control trials, participants controlled their own simulated self-motion, with the researcher giving them navigational instructions (when needed) to keep them on course. During each exposure, participants provided Fast Motion Sickness (FMS) scale ratings [from " 0 " (no sickness) to "20" (frank sickness)] every two minutes. Directly after each exposure, participants verbally rated the vection strength of that trial [from " 0 " (no vection) to "10" (strong vection)]. They then gave a "yes/no" response to the question: "did you feel motion sick during that trial?" And finally, they completed the post-exposure items of the SSQ. After completing the first trial on each day, participants had a forced rest period of at least ten minutes to minimize any symptom carry over to the next trial. During this time, they were instructed to sit down and await further instructions. The second trial for the day only began after their cybersickness severity ratings on the FMS scale fell below " 2 ".

\section{RESULTS}

\subsection{Identifying sick and well participants}

Participants were classified as either sick or well based on whether they verbally reported experiencing any cybersickness during the experiment. Well participants always responded "yes" to the question "do you feel well?", whereas sick participants responded "no" after at least one of the four trials. This resulted in 6 well participants ( 5 males and 1 female) and 14 sick participants (10 males and 4 females). Of the 14 sick participants, 3 reported feeling sick after only 1 of the 4 trials, 4 reported feeling sick after only 2 of the 4 trials, 2 reported feeling sick after 3 of the 4 trials, and 5 reported feeling sick after all 4 trials.

\subsection{Symptoms experienced by sick participants during HMD-based virtual reality}

The SSQ provides sub-scores that assess nausea (SSQ-N), disorientation (SSQ-D) and oculomotor (SSQ-O) symptoms. Figure 1 shows the average (post-pre) changes in these subscores for the 14 sick participants. Exposure to virtual reality produced the largest mean increase in symptom severity for SSQ-D $(M=35.3, S D=50.9)$. The next largest mean increase in symptom severity was found for SSQ-N $(M=29.6, S D=36.6)$ with the smallest increase in symptom severity being found for SSQ-O $(M=18.9, S D=30.7)$. This overall symptom profile 
(SSQ-D > SSQ-N > SSQ-O) appears to be consistent with most past findings for HMD-based cybersickness (see [7] for a review).

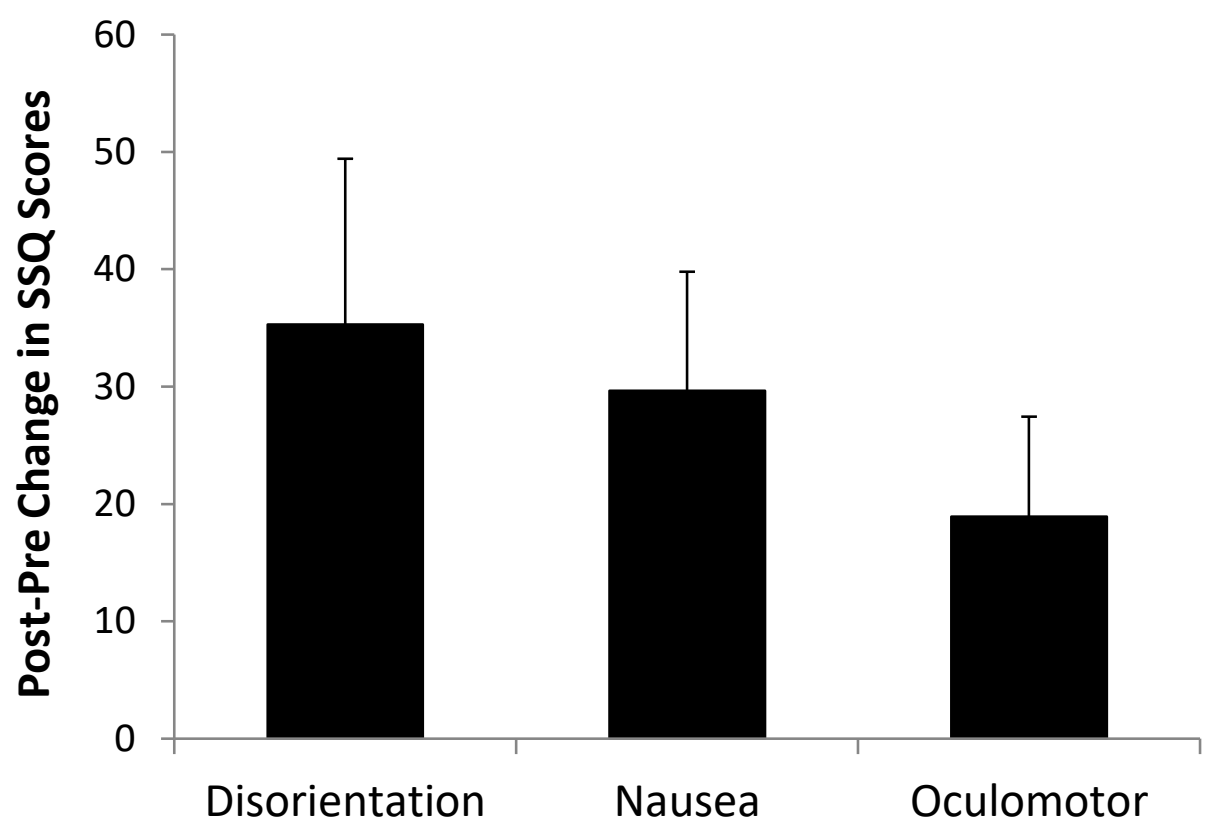

Fig. 1. Mean post-pre change in SSQ-D, SSQ-N, and SSQ-O sub-scores for the 14 sick participants in this study. Higher difference scores represent a greater increase in symptom severity. Error bars represent standard errors of the mean.

\subsection{Spontaneous postural activity}

Each participant's eyes-open and eyes-closed spontaneous postural activity was examined before each of the four different experimental trials. Sixteen samples of eyes-open, and four samples of eyes-closed, COP data were obtained for each of our 20 participants. This time series data was first smoothed, using a low-pass order-5 Butterworth filter and a cut-off frequency of $10 \mathrm{~Hz}$. Then the participant's positional variability was estimated for the sample by calculating the standard deviation of his/her COP along the anterior-posterior $(A / P)$ and the medial-lateral $(\mathrm{M} / \mathrm{L})$ axes. Eyes-open STDEV COP $_{\mathrm{A} / \mathrm{P}}$ and STDEV COPM/L did not vary significantly before the four different trials, $F(3,57)=2.549, p=0.065, \eta^{2}=0.118$ and $F(3,57)$ $=1.647, p=0.189, \eta^{2}=0.08$ respectively. Similarly, the eyes-closed STDEV COPA/P and STDEV $\mathrm{COP}_{\mathrm{M} / L}$ also did not vary significantly before the four different trials, $F(3,57)=0.738, p=0.533$, $\eta^{2}=0.037$ and $F(3,57)=0.773, p=0.514, \eta^{2}=0.039$ respectively. These null findings suggest 
that STDEV COP $\mathrm{A} / \mathrm{P}$ and STDEV COP $\mathrm{M} / \mathrm{L}$ could be suitable for classifying individuals as more/less naturally stable. The mean eyes-open and eyes-closed STDEV COP $_{\mathrm{A} / \mathrm{P}}$ and STDEV COP $\mathrm{M} / \mathrm{L}$ for the 20 different participants are shown in Figures 2 and 3.
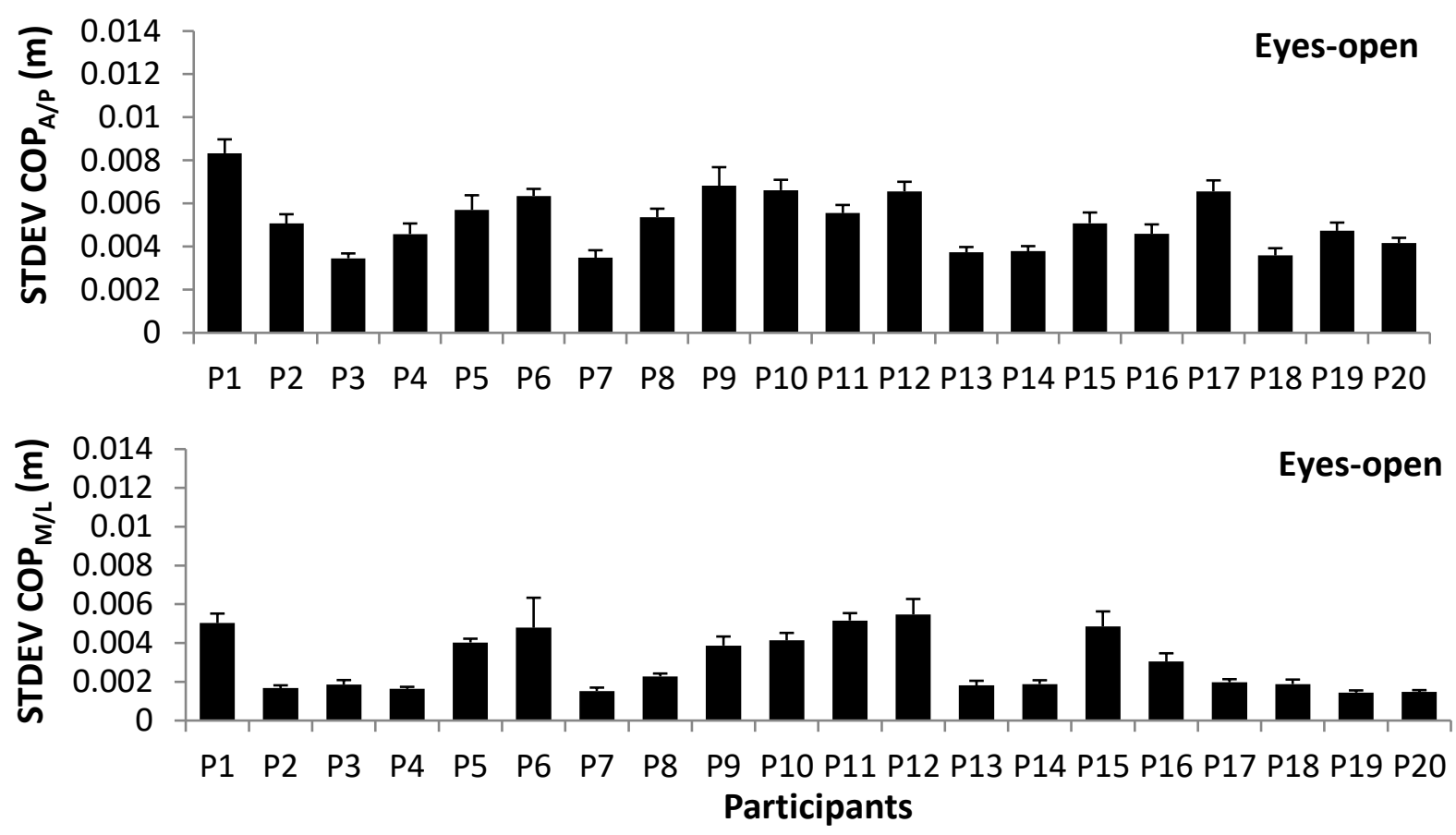

Fig.2. Mean eyes-open STDEV $\operatorname{COP}_{\mathrm{A} / \mathrm{P}}$ (Top) and STDEV COP $\mathrm{M/L}$ (Bottom) values for the twenty participants. Error bars represent standard error of the mean. 


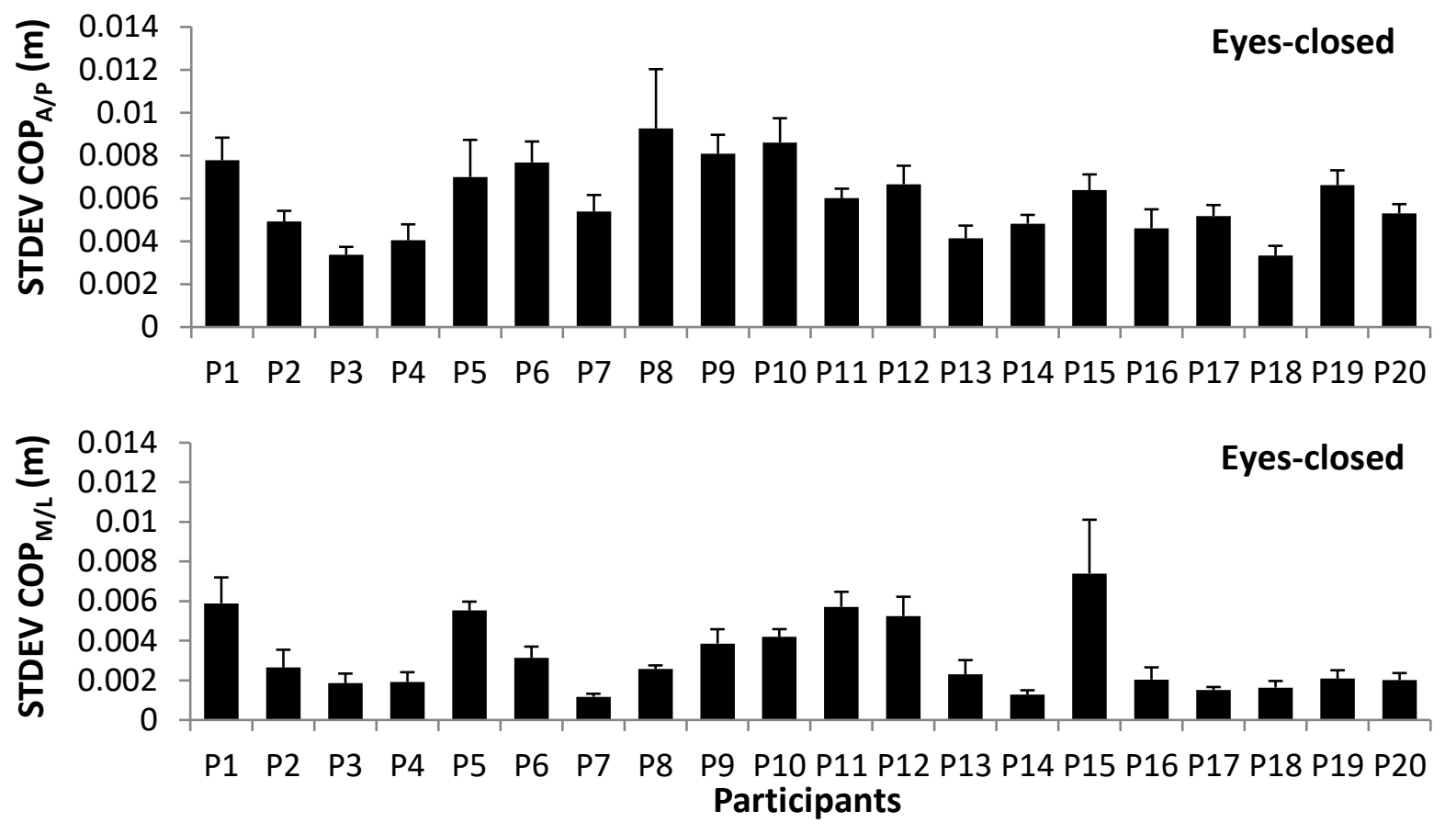

Fig.3. Mean eyes-closed STDEV $\operatorname{COP}_{\mathrm{A} / \mathrm{P}}$ (Top) and STDEV COP $\mathrm{M} / \mathrm{L}$ (Bottom) values for the twenty participants. Error bars represent standard error of the mean.

The temporal dynamics of this spontaneous postural activity was next examined by conducting detrended fluctuation analyses (DFAs) on the COP data for each axis [73]. The scaling exponent $\alpha$ of these DFAs measured the extent to which the COP was self-similar over different timescales (with $\alpha>0.5$ indicating autocorrelation at some timescale, $\alpha=1$ representing the maximum possible self-similarity, and $\alpha=1.5$ indicating brown noise). In this study, DFA $\alpha$ values ranged from 1.3 to 1.7 along the A/P axis, and from 1.1 to 1.7 along the $\mathrm{M} / \mathrm{L}$ axis - confirming that our COP recordings were non-stationary data. Eyes-open DFA $\alpha_{A / P}$ and DFA $\alpha_{M / L}$ values did not vary significantly before the four different trials, $F(3,57)=$ 1.299, $p=0.284, \eta^{2}=0.064$ and $F(3,57)=1.763, p=0.164, \eta^{2}=0.085$ respectively. While eyes-closed DFA $\alpha_{\mathrm{A} / \mathrm{P}}$ values also did not vary significantly $\left(F(3,57)=0.350, p=0.789, \eta^{2}=\right.$ $0.018)$, there was a significant effect of trial on eyes-closed DFA $\alpha_{M} / L$ values $(F(3,57)=2.915$, $\left.p=0.042, \eta^{2}=0.133\right)$. The former null findings suggested that eyes-open DFA $\alpha_{A} / P$ and DFA $\alpha_{M / L}$, as well as eyes-closed DFA $\alpha_{A / P}$ (but possibly not eyes-closed DFA $\alpha_{M / L}$ ), were suitable for classifying individuals as more/less naturally stable. The mean eyes-open and eyes-closed DFA $\alpha_{A / P}$ and $\alpha_{M / L}$ values for each participant are shown in Figures 4 and 5 . 


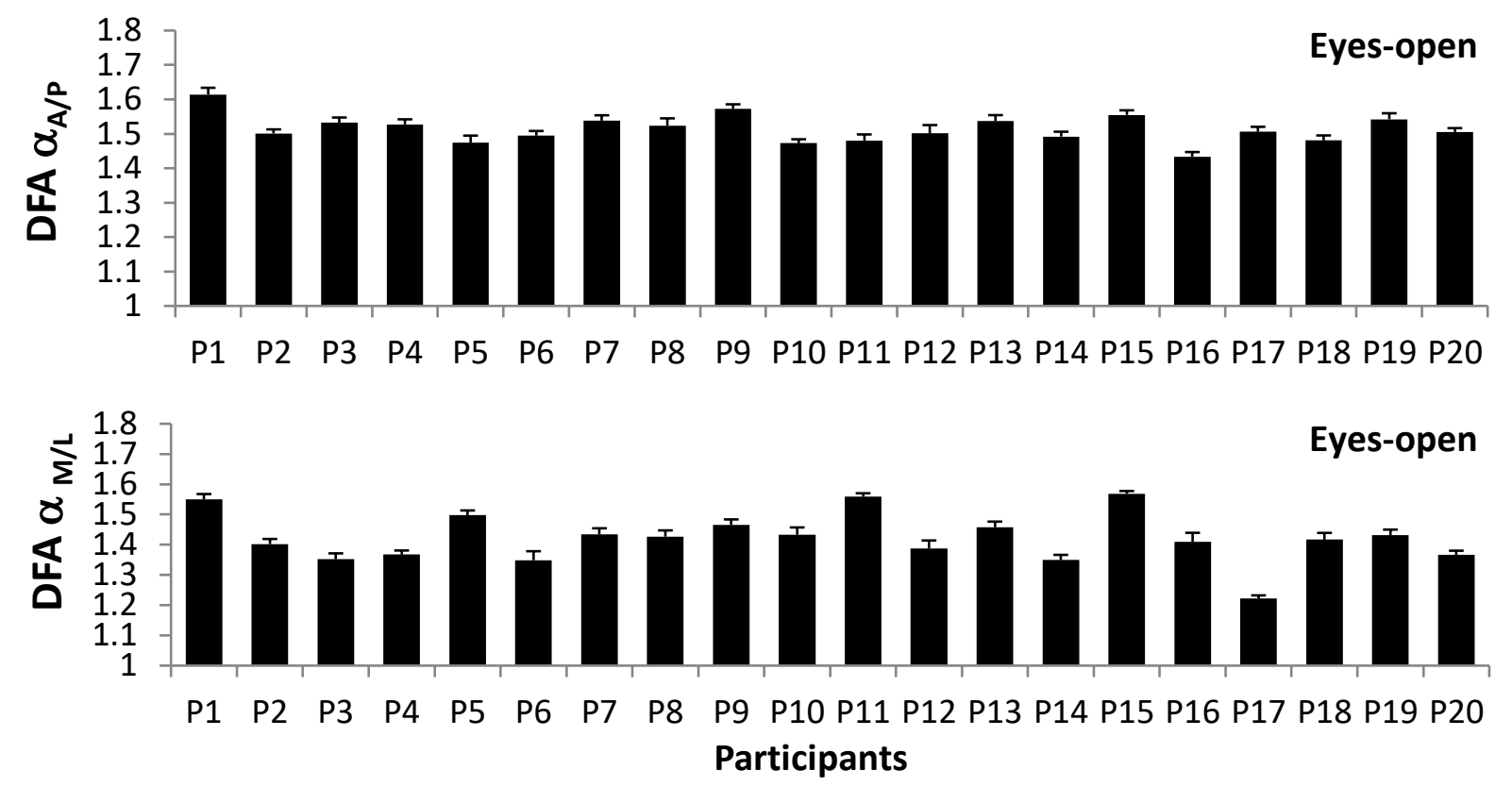

Fig.4. Mean eyes-open DFA $\alpha_{A / P}$ (Top) and DFA $\alpha_{M / L}$ (Bottom) values for the twenty participants. Error bars represent standard error of the mean.

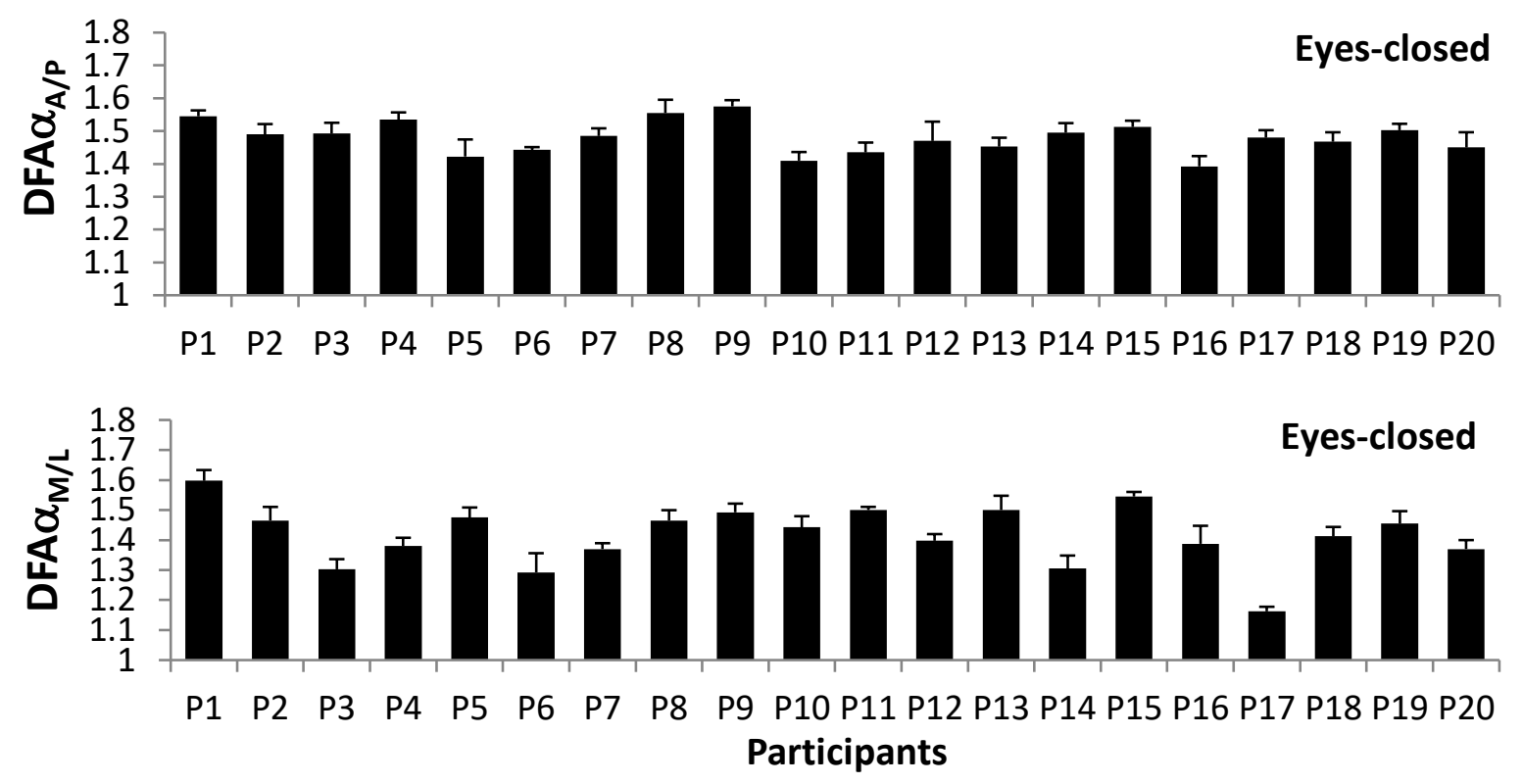

Fig. 5. Mean eyes-closed DFA $\alpha_{A / P}$ (Top) and DFA $\alpha_{M / L}$ (Bottom) values for the twenty participants. Error bars represent standard error of the mean.

\subsection{Differences in spontaneous postural activity between sick and well participants}

Independent samples t-tests were conducted to see if our sick and well participants differed in terms of their eyes-open and eyes-closed spontaneous postural activity. Sick participants $(M=1.53, S D=0.04)$ were found to produce significantly larger eyes-open DFA 
$\alpha_{\mathrm{A} / \mathrm{P}}$ values than the well participants $(M=1.49, S D=0.03), t(18)=2.29, p=0.03$, two-tailed, $d=1.12$ (see Figure 6 Left). Similarly, sick participants $(M=1.50, S D=0.04$ ) were also found to have significantly larger eyes-closed DFA $\alpha_{\mathrm{A} / \mathrm{P}}$ values than the well participants $(M=1.43$, $S D=0.03$ ) $, t(18)=3.857, p=0.001$, two-tailed, $d=1.88$ (see Figure 6 Right). However, sick and well participants were not found to differ significantly in either their eyes-open or their

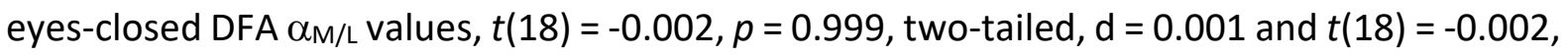
$p=0.998$, two-tailed, $\mathrm{d}=0.001$ respectively.

While we found significant differences in the temporal dynamics of our sick and well participants' postural activity, they did not appear to differ significantly in terms of either their eyes-open or eyes-closed positional variability. Specifically, sick and well participants did not differ in eyes-open STDEV COP $\mathrm{A} / \mathrm{P}$ or eyes-open STDEV COP $\mathrm{M} / \mathrm{L}, t(18)=-0.832, p=0.417$, twotailed, $\mathrm{d}=0.46$ and $t(18)=-0.817, p=0.08$, two-tailed, $\mathrm{d}=0.95$. They also did not differ in

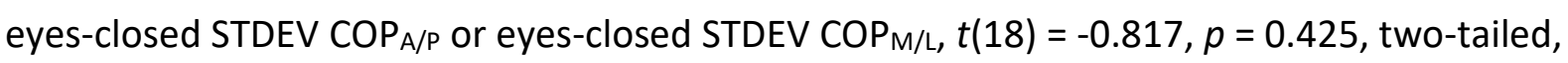
$\mathrm{d}=0.04$ and $t(18)=-0.859, p=0.402$, two-tailed, $d=0.04$.
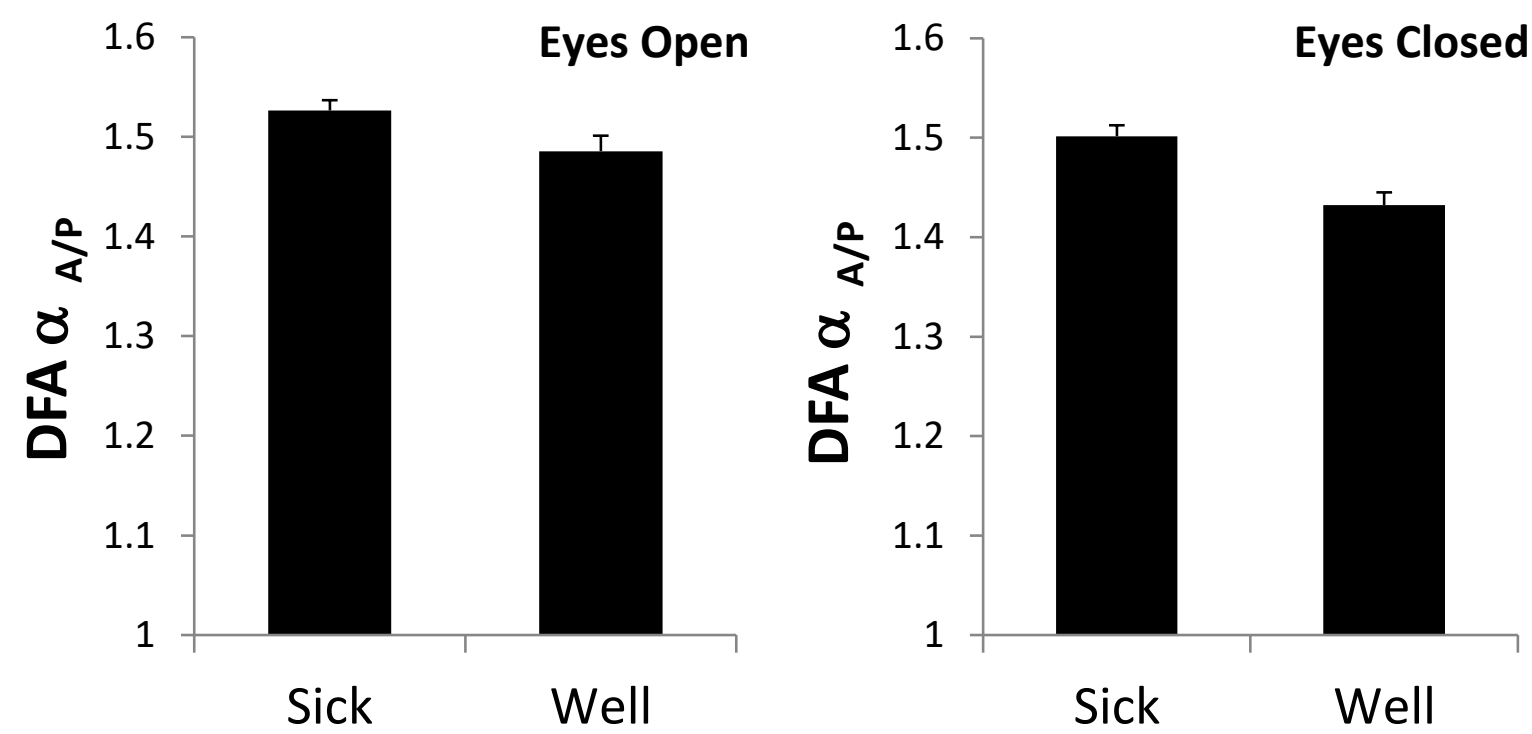

Fig. 6. DFA $\alpha_{A / P}$ values for sick and well participants with their eyes-open (left) or eyes-closed (right). Error bars represent the standard error of the mean.

\subsection{Effects of SUPPORT TYPE, CONTROL TYPE and TIME IN TRIAL on cybersickness severity}

During each of the four different trials participants rated the severity of their cybersickness every 2 minutes from 0-20 using the FMS scale. A 2 (SUPPORT TYPE: Postural 
restraint or Free-standing) $\times 2$ (CONTROL TYPE: Active Control or Passive Viewing) $\times 5$ (TIME IN TRIAL: 2, 4, 6, 8 or 10 minutes) repeated measures ANOVA was used to examine these FMS scores. The main effect of TIME IN TRIAL was found to be significant, $F(1.422,25.594)=8.896$, $p=0.003, \eta^{2}=0.33$. As can be seen in Figure 7, cybersickness severity increased in a linear fashion with TIME IN TRIAL from 2 to 10 minutes. However, the other main effects of SUPPORT TYPE $\left(F(1,18)=0.402, p=0.534, \eta^{2}=0.02\right)$ and CONTROL TYPE $(F(1,18)=1.383, p=$ $0.255, \eta^{2}=0.07$ ) both failed to reach significance. None of the 2- or 3-way interactions were found to be significant.

\subsection{Effect of TESTING DAY and SESSION on cybersickness severity}

We also conducted an additional 2 (TESTING DAY: Day 1 or Day 2 ) $\times 2$ (SESSION: First or Second for each day) x 5 (TIME IN TRIAL: 2, 4, 6, 8 or 10 minutes) repeated measures ANOVA on the FMS scores. We found a significant main effect of DAY, $F(1,18)=17.814, p=0.001, \eta^{2}$ $=0.497$. This revealed that the cybersickness on Day $1(M=4.089)$ was significantly more severe than cybersickness on Day $2(M=2.332)$. However, the main effect of SESSION was not significant, $F(1,18)=1.383, p=0.255, \eta^{2}=0.071$. We again found a significant main effect of TIME IN TRIAL, $F(1.422,25.594)=8.896, p=0.003, \eta^{2}=0.331$. We also found a significant interaction between TESTING DAY and TIME IN TRIAL, $F(4,72)=2.959, p=0.025, \eta^{2}=0.141$. As can be seen in Figure 8, the rate of increase in cybersickness as a function of TIME IN TRIAL was steeper on Day 1 than Day 2 (the slopes of the lines of best fit for the FMS scores as a function of TIME IN TRIAL were 0.33 for Day 1 and 0.2 for Day 2). No other 2- or 3-way interactions were found to reach significance. 


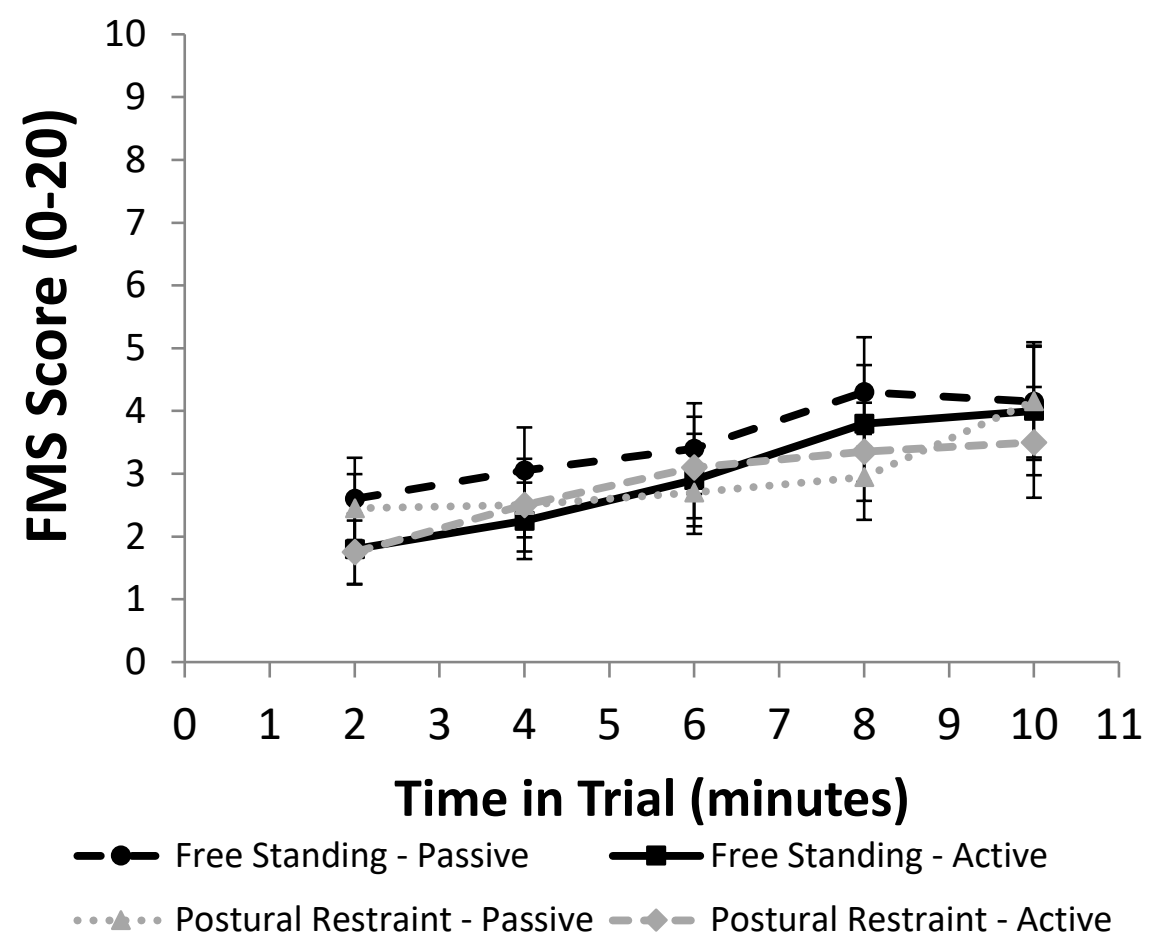

Fig. 7. Effect of Time in Trial on cybersickness severity (FMS scores) for the four different trials (Free Standing - Passive, Free Standing - Active, Postural Restraint - Passive and Postural Restraint - Active). Error bars represent the standard error of the mean.

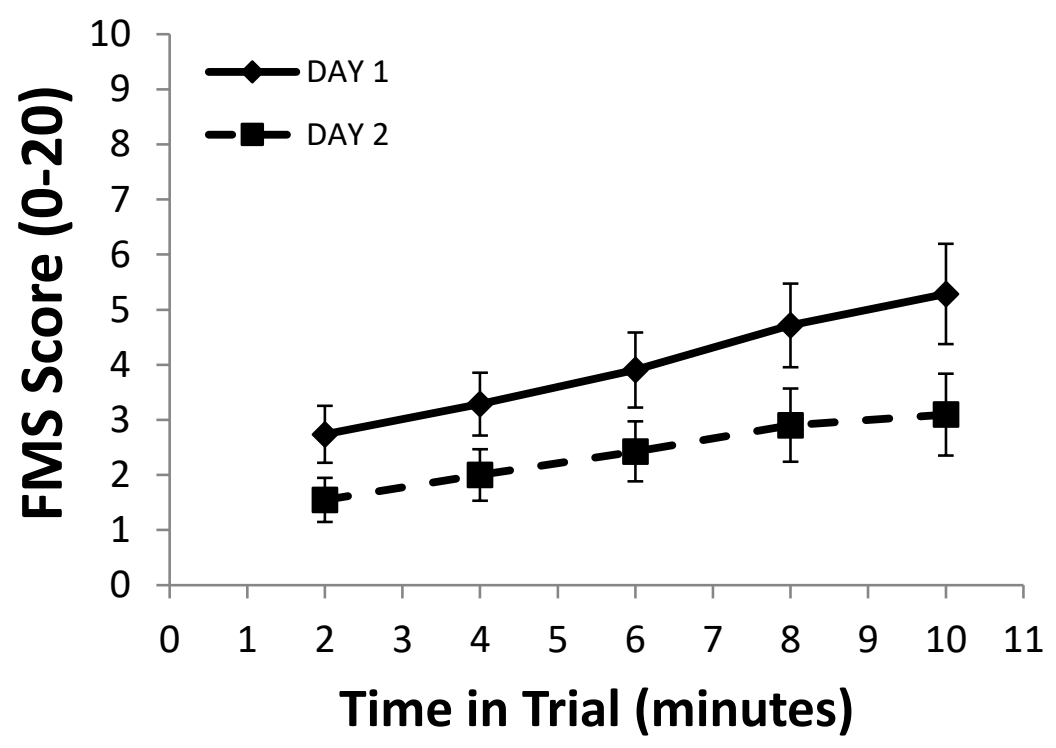

Fig. 8. Effects of Time in Trial and Testing Day on cybersickness severity (FMS scores). Error bars represent the standard error of the mean. 


\subsection{Effects of SUPPORT TYPE, CONTROL TYPE and TIME IN TRIAL on vection}

After each of the four different experimental trials participants rated the strength of their experience of vection. A 2 (SUPPORT TYPE: Postural restraint or Free-standing) $\times 2$ (CONTROL TYPE: Active Control or Passive Viewing) repeated measures ANOVA was used to examine this vection data. The main effects of SUPPORT TYPE $\left(F(1,19)=0.028, p=0.868, \eta^{2}\right.$ $=0.001)$ and CONTROL TYPE $\left(F(1,19)=0.056, p=0.816, \eta^{2}=0.003\right)$, as well as the SUPPORT TYPE by CONTROL TYPE interaction $\left(F(1,19)=0.485, p=0.495, \eta^{2}=0.025\right)$ were all nonsignificant.

\subsection{Effects of TESTING DAY and SESSION on vection}

We also conducted an additional 2 (TESTING DAY: Day 1 or Day 2) $\times 2$ (SESSION: First or Second for each day) repeated measures ANOVA on vection strength ratings. The main effects of TESTING DAY $\left(F(1,19)=0.079, p=0.781, \eta^{2}=0.004\right)$ and SESSION $(F(1,19)=0.056$, $\left.p=0.815, \eta^{2}=0.003\right)$, as well as the TESTING DAY by SESSION interaction $(F(1,19)=0.080, p=$ $\left.0.780, \eta^{2}=0.004\right)$ were all non-significant.

\subsection{Relationship between cybersickness severity and vection strength}

We also examined the relationship between cybersickness severity and vection strength for this experiment. As correlational and regression-based analyses assume that the data represents independent samples [74], we first averaged our FMS scores and vection strength ratings across the four different experimental trials. This produced one pair of data points for each of the 20 participants (i.e., their average FMS score and their average vection strength rating). We found a significant positive relationship between their average vection strength ratings and their average FMS scores, $R^{2}=0.28, F(1,19)=6.989, p=0.017$. That is, participants who experienced stronger vection also tended to report more severe cybersickness. 


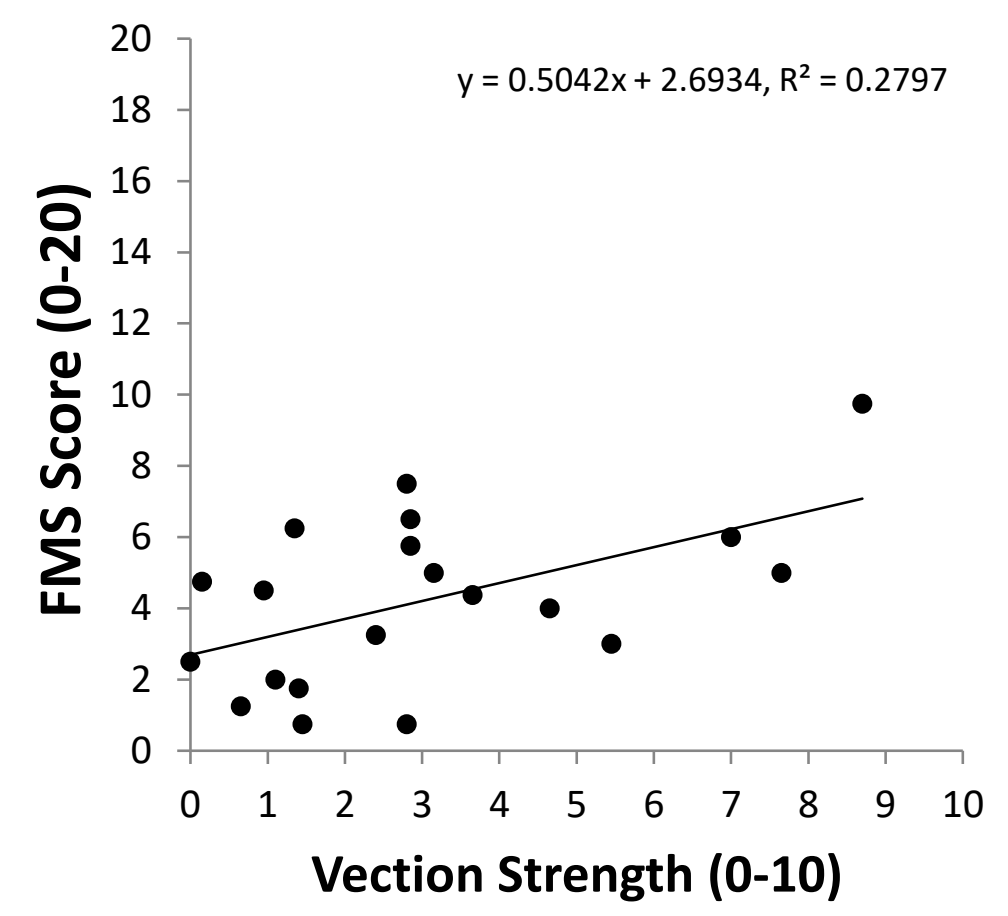

Fig. 9. Relationship between average vection strength ratings and the averaged FMS scores for our 20 participants. The trendline indicates the significant positive relationship between vection and cybersickness severity.

\section{DISCUSSION}

In this study we were interested in: 1) identifying the individuals who were more susceptible to HMD-based cybersickness; and 2) testing various methods/techniques to generally reduce the severity of this cybersickness.

Individual Differences in Postural Instability and Cybersickness

Consistent with recent findings by Munafo et al. [60] and Arcioni et al. [8], we found evidence that participants who became sick when exposed to virtual reality had different spontaneous postural activity compared to those who remained well. We estimated each participant's positional variability (STDEV COP $_{\mathrm{A} / \mathrm{P}}$ and STDEV COP $\mathrm{M} / \mathrm{L}$ ) and movement temporal dynamics (DFA $\alpha_{A / P}$ and DFA $\alpha_{M / L}$ ). On average, the sick participants displayed higher DFA $\alpha_{A / P}$ values before donning their HMDs than the well participants (who always reported that they were not sick during all of their exposures to virtual reality). These sick versus well differences in DFA $\alpha_{\mathrm{A} / \mathrm{P}}$ were found both when participants had their eyes closed and when 
they stood quietly looking at their stationary laboratory surroundings (that is, under conditions which should not have induced any vection). These sick versus well differences in DFA $\alpha_{A / P}$ appear to be similar to several past findings for visually induced motion sickness (e.g., [47] and [58]). Such findings (that pre-exposure postural activity before donning the HMD predicts subsequent motion sickness) might appear to be challenging for vection-based theories of cybersickness to explain. Although recent research has found evidence that spontaneous postural instability appears to predict both vection and visually induced motion sickness when participants are later exposed to global patterns of optic flow [75].

While the current study examined postural activity prior to HMD-based gameplay, future studies also need to investigate postural activity during HMD-based gameplay. Studies have shown that certain patterns of postural motion precede the onset of sickness symptoms during exposure to external motion displays and physical scene motions. However, research is still needed to confirm that standing postural activity also changes just prior to the users' first reports of cybersickness during HMD-based virtual reality.

\section{Effects of Postural Restraints and Active Control}

This study also examined the effect of using postural restraints on cybersickness. Based on the findings of several previous studies on visually-induced motion sickness $[47,62]$, postural restraints were expected to reduce HMD-based cybersickness. However, while the use of restraints should have increased the postural stability of our participants, they were not found to significantly alter cybersickness (compared to free-standing conditions). Thus, at first glance, support for the postural instability theory of cybersickness appears mixed. Consistent with the theory, individual differences in spontaneous postural activity appeared to predict subsequent susceptibility to HMD-based cybersickness. But contrary to predictions, the use of our postural restraints did not reduce the cybersickness in this study ${ }^{1}$. However, it is possible that our SUPPORT TYPE manipulation was not a fair test of postural instability theory, because participants had to lean forwards to engage the ceiling-mounted postural restraint. While this leaning was not expected to increase motion sickness (based

\footnotetext{
${ }^{1}$ We acknowledge that the postural restraint condition used in this study was unusual, with participants leaning into the harness and their bodies being held in place by their own weight. We chose to examine this condition as we believed that it had some ecological validity - standing HMD users might choose to play in such a harness to ensure that they do not fall over and injure themselves during gameplay.
} 
on [76]), a number of our participants reported that being secured in this fashion "felt odd" and "was something they had not experienced before". This suggests that they might not have had the appropriate postural control strategies for this unfamiliar situation. It was also possible that some of our participants might have misperceived vertical when they were leaning (as opposed to when they were free-standing and upright). According to detailed sensory conflict theory, such misperceptions could have cancelled any potential benefits provided by the use of postural restraints (see [77]). Future studies therefore need to reexamine the effects of postural restraints on HMD-based cybersickness when participants are supported in an upright (as opposed to a leaning) position.

Contrary to the findings of several past studies on visually induced motion sickness $[63,65]$, we did not find that active control produced less cybersickness than passive viewing. However, it should be noted that active control trials were always presented after passive viewing trials in the current study. Thus, it is possible that the active control trials were contaminated by the sickness experienced in the preceding passive viewing trials. While this could potentially explain our failure to find significant differences in cybersickness between active and passive trials, it should be noted that the active trials only commenced after the participant's cybersickness severity ratings had fallen below " 2 " on the FMS scale. Another possible issue was the strength of our active control versus passive viewing manipulation. One of our reviewers noted that using video recordings of previous game sessions for the passive viewing conditions (instead of having the experimenter control the gameplay in realtime as we did) might have strengthened this manipulation. However, viewing these video playbacks might also have introduced multisensory conflicts (due to the absence of non-visual stimulation during display segments produced by head-movements in the original recordings). Our passive viewing conditions had the advantage that any involuntary headmovements were incorporated directly into the visual displays (as they were during the active control conditions).

\section{Effects of Exposure Duration and Day of Testing}

As predicted, we did find significant effects of both exposure duration and the day of testing on cybersickness. Participants were exposed twice to 10-minutes of virtual reality on each of the two testing days. As expected, within each of the four separate exposures, cybersickness was found to steadily increase with the user's time in trial. Consistent with past 
findings on visually induced motion sickness (e.g. [62,70]) and HMD-based cybersickness [69], the cybersickness in our study was significantly reduced on the second day of testing (compared to the first). Interestingly we also found that the rate at which cybersickness increased as a function of time in trial was reduced in trials 3 and 4 on day 2 (compared to trials 1 and 2 on day 1$)$.

While we found significant differences in the cybersickness across the two testing days, repeated exposures to virtual reality within each testing day did not significantly reduce cybersickness. These null findings suggest that at least 20-minutes of exposure to HMD-based virtual reality was required to significantly reduce cybersickness (see also $[26,67,69]$ ). However, another possible interpretation of these findings is that participants adapted or habituated better across the two testing days because they received identical exposures to virtual reality on both days (i.e., always 10-minutes of passive viewing followed by 10 -minutes of active control). By contrast, participants were given rather different virtual experiences on the two trials tested on each day (the first trial for the day being passive viewing only and the last trial for the day requiring the user to actively control the simulation).

\section{Relationship between Vection and Cybersickness}

In addition to measuring cybersickness, we also measured the strength of the vection induced by the four experimental trials (i.e., free standing - passive, free standing - active, postural restraint - passive, postural restraint - active). Consistent with a vection-based explanation of cybersickness, we found that on average participants who experienced stronger vection tended to report more severe cybersickness. Also consistent with this explanation, our SUPPORT TYPE and CONTROL TYPE manipulations appeared to have little effect on both vection strength and cybersickness. Moderate vection strength was maintained throughout the experiment, with no significant effects found across the four SUPPORT TYPE by CONTROL TYPE conditions. However, it should be noted that while we found a marked reduction in cybersickness from day 1 to day 2 , there was no significant difference in the strength of the vection experienced on day 1 and day 2 . As past findings on this topic are rather mixed, this suggests that we should be cautious when interpreting the positive relationship between vection and cybersickness observed in the current study.

\section{CONCLUSIONS}


The current study investigated the effects of postural stability, active control, exposure duration and repeated presentation on the cybersickness induced by HMD-based virtual reality. Consistent with the postural instability theory of cybersickness, sick and well participants in our study appeared to differ in their spontaneous postural activity before they entered virtual reality. We also found a significant relationship between vection and cybersickness in this study, where participants who experienced stronger vection also tended to report more severe cybersickness. Thus, these findings also appear to provide some support for sensory-conflict or vection-based explanations of cybersickness. Contrary to our predictions, we found no overall effect of postural restraint or active locomotion control on cybersickness in this study. However, the study was somewhat underpowered (given the number of factors examined). Therefore we recommend that these two findings in particular be confirmed in future studies with larger sample sizes.

Importantly, cybersickness was found to steadily increase with the time spent in each exposure to virtual reality. This cybersickness also decreased markedly on the second day of testing and the rate of the increase in cybersickness as a function of exposure time was also reduced on day 2 . Thus it would appear that the unpleasant side-effects of HMD-based virtual reality can decrease rapidly with a few repeated exposures.

The current findings suggest that it should: 1 ) be possible to identify individuals who are more at risk of HMD-based cybersickness; and 2) reduce the severity of their cybersickness in the future by repeated exposures to this type of virtual reality. It will however be important for future research to determine whether the benefits provided by repeated exposures to one type of HMD-based virtual reality generalize to other types of HMD-based virtual reality. 


\section{REFERENCES}

[1] F. Alwadani, M.S. Morsi, Pixeye virtual reality training has the potential of enhancing proficiency of laser trabeculoplasty performed by medical students: A pilot study, Middle East African Journal of Ophthalmology 19 (2012) 120-122.

[2] A. Y. Lee, M. P. Fried, M. Gibber, Improving rhinology skills with simulation, Otolaryngologic Clinics of North America 50(5) (2017) 893-901. doi:10.1016/j.otc.2017.05.002

[3] R.M. Pot-Kolder, C.N. Geraets, W. Veling, M. van Beilen, A.B. Staring, H.J. Gijsman, P.A. Delespaul, M. van der Gaag, Virtual-reality-based cognitive behavioural therapy versus waiting list control for paranoid ideation and social avoidance in patients with psychotic disorders: a single-blind randomised controlled trial, The Lancet Psychiatry 5 (2018) 217-26.

[4] K. Bhagat, W. Liou, C. Chang, A cost-effective interactive 3D virtual reality system applied to military live firing training, Virtual Reality 20 (2016) 127-140.

[5] X. Liu, Y. Liu, X. Zhu, M. An, F. Hu, Virtual reality based navigation training for astronaut moving in a simulated space station. Lecture Notes in Computer Science, (2016) pp.416423.

[6] G. Isabwe, M. Moxnes, M. Ristesund, D. Woodgate, Children's interactions within a virtual reality environment for learning chemistry. Advances in Intelligent Systems and Computing, (2017), 221-233.

[7] L. Rebenitsch, C. Owen, Review on cybersickness in applications and visual displays, Virtual Real. 20(2) (2016) 101-125.

[8] B. Arcioni, S. Palmisano, D. Apthorp, J. Kim, Postural stability predicts the likelihood of cybersickness in active HMD-based virtual reality. Displays. (2019).

[9] F. Bonato, A. Bubka, S. Palmisano, Combined pitch and roll and cybersickness in a virtual environment, Aviat. Space Environ. Med. 80 (2009) 941-945.

[10] J.J. LaViola, A discussion of cybersickness in virtual environments, ACM SIGCHI Bull. 32 (2000) 47-56.

[11] S. Sharples, S. Cobb, A. Moody, J.R. Wilson, Virtual reality induced symptoms and effects (VRISE): Comparison of head mounted display (HMD), desktop and projection display systems, Displays 29 (2008) 58-69. 
[12] Y.Y. Kim, H.J. Kim, E.N. Kim, H.D. Ko, H.T. Kim, Characteristic changes in the physiological components of cybersickness, Psychophysiology 42(5) (2005) 616-662.

[13] B.D. Lawson, Motion sickness symptomatology and origins, in: K.S. Hale, K.M. Stanney (Eds.), Handbook of Virtual Environments; Design, Implementation, and Applications, CRC Press, Boca Raton, 2015, pp. 531-600.

[14] J. Reason, J. Brand. Motion Sickness, (1975) Academic Press, London.

[15] J.T. Reason, Motion sickness adaptation: a neural mismatch model, J. R. Soc. Med. 71 (1978) 11.

[16] G.E. Riccio, T.A. Stoffregen, An ecological theory of motion sickness and postural instability, Ecological Psychol. 3 (1991) 195-240.

[17] S. Ebenholtz, M. Cohen, B. Linder. The possible role of nystagmus in motion sickness, Aviat. Space Environ. Med. 65 (1994) 1032-1035.

[18] M. Treisman. Motion sickness: An evolutionary hypothesis, Science 197 (1977) 493 495.

[19] C.M. Oman, Motion sickness: a synthesis and evaluation of the sensory conflict theory, Can. J. Physiol. Pharmacol. 68 (1990) 294-303.

[20] J.E. Bos, W. Bles, E.L. Groen, A theory on visually induced motion sickness, Displays 29 (2008) 47-57.

[21] J. Kim, C.Y. Chung, S. Nakamura, S. Palmisano, S.K. Khuu, The Oculus Rift: a cost-effective tool for studying visual-vestibular interactions in self-motion perception, Front. Psychol. 6 (2015) 248.

[22] B.E. Riecke, D. Feuereissen, To move or not to move: can active control and user-driven motion cueing enhance self-motion perception (vection) in virtual reality? In: Proceedings of the ACM Symposium on Applied Perception 2012, ACM, Los Angeles, CA, 2012, pp. 17-24.

[23] S. Palmisano, R.S. Allison, M.M. Schira, R.J. Barry, Future Challenges for Vection Research: Definitions, Functional Significance, Measures and Neural Bases. Frontiers in Psychology, 6 (2015) 1-15.

[24] L.J. Hettinger, K. Berbaum, R. Kennedy, W.P. Dunlap, M.D. Nolan, Vection and simulator sickness, Military Psychol. 2 (1990) 171-181.

[25] M.E. McCauley,T.J. Sharkey, Cybersickness:perception of self-motion in virtual environments, Presence 1 (1992) 311-318. 
[26] K.J. Hill, P.A. Howarth, Habituation to the side effects of immersion in a virtual environment, Displays 21 (2000), 25-30.

[27] B. Keshavarz, B.E. Riecke, L.J. Hettinger, J.L. Campos, Vection and visually induced motion sickness: how are they related? Front Psychol. 6 (472) (2015) 1-11.

[28] S. Palmisano, R.S., Allison, R.S., J., Kim, F. Bonato. Simulated Viewpoint jitter shakes sensory conflict accounts of self-motion perception, Seeing \& Perceiving 24 (2011) 173200.

[29] S. Weech, J.P. Varghese, M. Barnett-Cowan, Estimating the sensorimotor components of cybersickness, Journal of neurophysiology 120(5) (2018) 2201-2217.

[30] G.L. Zacharias, L.R. Young, Influence of combined visual and vestibular cues on human perception and control of horizontal rotation, Exp. Brain Res. 41 (1981) 159-171.

[31] F. Bonato, A. Bubka, L. Alfieri, Display color affects motion sickness symptoms in an optokinetic drum. Aviat. Space Environ. Med. 75 (2004) 306-311.

[32] F. Bonato, A. Bubka., M. Story, Rotation direction change hastens motion sickness onset in an optokinetic drum, Aviat. Space Environ. Med. 76 (2005) 823-827.

[33] C. Diels, K. Ukai, P.A. Howarth, Visually induced motion sickness with radial displays: Effects of gaze angle and fixation, Aviat., Space Environ. Med. 78(7) (2007) 659-665.

[34] M.B. Flanagan, J.G. May, T.G. Dobie, Optokinetic Nystagmus, vection and motion sickness. Aviat. Space and Environ. Med. 73 (2002) 1067-73.

[35] S.A.E. Nooij, P. Pretto, D. Oberfeld, H. Hecht, H.H. Bülthoff. Vection is the main contributor to motion sickness induced by visual yaw rotation: Implications for conflict and eye movement theories, PLoS One 12(4) (2017) e0175305. https://doi.org/10.1371/journal.pone.0175305

[36] S. Palmisano, F. Bonato, A. Bubka, J. Folder, Vertical display oscillation increases vection in depth and simulator sickness. Aviat. Space Environ. Med. 78(10) (2007) 951-956.

[37] L.J. Smart, T.A. Stoffregen, B.G. Bardy, Visually induced motion sickness predicted by postural instability. Human Factors 44 (2002) 451-465.

[38] F. Bonato, A. Bubka, A., S. Palmisano, D. Phillip, G. Moreno, G, Vection change exacerbates simulator sickness in virtual environments, Presence: Teleoperators and Virtual Environments, 17(3) (2008) 283-292.

[39] J.T. Ji, R.H. So, R.T. Cheung, Isolating the effects of vection and optokinetic nystagmus on optokinetic rotation-induced motion sickness, Human Factors 51(5) (2009) 739-751. 
[40] J.F. Golding, K. Doolan, A. Acharya, M. Tribak, M.A. Gresty, Cognitive cues and visually induced motion sickness. Aviat. Space Environ. Med. 83 (2012) 477-482.

[41] B. Keshavarz, L.J. Hettinger, D. Vena, J.L. Campos. Combined effects of auditory and visual cues on the perception of vection. Exp. Brain Res. 232 (2014) 827-836.

[42] B.D. Lawson. Exploiting the illusion of self-motion (vection) to achieve a feeling of 'virtual acceleration' in an immersive display, in: Proceedings of the 11th International Conference on Human-Computer Interaction 2005, Las Vegas, NV, 2005, pp. 1-10.

[43] S. Palmisano, R. Mursic, J. Kim, Vection and cybersickness generated by head-anddisplay motion in the Oculus Rift, Displays 46 (2017) 1-8.

[44] B.E. Riecke, J.D. Jordan. Comparing the effectiveness of different displays in enhancing illusions of self-movement (vection), Frontiers in Psychology 6(713) (2015) doi:10.3389/fpsyg.2015.00713

[45] N.A. Webb, M.J. Griffin, M.J. Eye movement, vection, and motion sickness with foveal and peripheral vision, Aviation Space and Environmental Medicine, 74 (2003) 622-625.

[46] C.T. Bonnet, E. Faugloire, M.A. Riley, B.G. Bardy, T.A. Stoffregen, Motion sickness preceded by unstable displacements of the center of pressure, Hum. Mov. Sci. 25 (2006) 800-820.

[47] C. Chang, W. Pan, F. Chen, T.A. Stoffregen, Console video games, postural activity, and motion sickness during passive restraint, Exp. Brain Res. 229 (2013) 235-242.

[48] C. Chang, W. Pan, L., Tseng, T.A. Stoffregen, Postural activity and motion sickness during video game play in children and adults, Exp. Brain Res. 217 (2012) 299-309.

[49] J., Chardonnet, M.A. Mirzaei, F. Mérienne, Features of the postural sway signal as indicators to estimate and predict visually induced motion sickness in virtual reality, International J. Human-Computer Interact. 33 (2017) 771-785. doi: 10.1080/10447318.2017.1286767

[50] E., Faugloire, C.T. Bonnet, M.A. Riley, B.G. Bardy, T.A. Stoffregen, Motion sickness, body movement, and claustrophobia during passive restraint, Exp. Brain Res. 177 (2007) 520532.

[51] F. Koslucher, E. Haaland, T.A. Stoffregen, Body load and the postural precursors of motion sickness, Gait \& Posture 39 (2014) 606-10.

[52] N. Owen, A.G. Leadbetter, L. Yardley, Relationship between postural control and motion sickness in healthy subjects, Brain Res. Bull. 47 (1998) 471-474. 
[53] T.A. Stoffregen, F.-C. Chen, F.C. Koslucher, Motion control, motion sickness, and the postural dynamics of mobile devices, Exp. Brain Res. 232 (2014) 1389-1397.

[54] T.A. Stoffregen, E. Faugloire, K. Yoshida, M.B. Flanagan, O. Merhi, Motion sickness and postural sway in console video games, Hum Factors 50 (2008) 322-331. doi: $10.1518 / 001872008 \times 250755$

[55] T.A. Stoffregen, L.J. Hettinger, M.W. Haas, M.M. Roe, L.J. Smart, Postural instability and motion sickness in a fixed-base flight simulator, Hum. Factors 42 (2000) 458-469.

[56] T.A. Stoffregen, L.J. Smart, Postural instability precedes motion sickness, Brain Res. Bull. 47 (1998) 437-448.

[57] T.A., Stoffregen, K. Yoshida, S., Villard, L., Scibora, B.G. Bardy, Stance Width Influences Postural Stability and Motion Sickness, Ecological Psychol. 22 (2010) 169-191.

[58] S.J. Villard, M.B. Flanagan, G.M. Albanese, T.A. Stoffregen, Postural instability and motion sickness in a virtual moving room, Hum. Factors 50 (2008) 332-345.

[59] Y. Yokota, M. Aoki, K. Mizuta, Y. Ito, N. Isu, Motion sickness susceptibility associated with visually induced postural instability and cardiac autonomic responses in healthy subjects, Acta oto-laryngologica 125 (2005) 280-285.

[60] J. Munafo, M., Diedrick, T.A. Stoffregen, T. A., The virtual reality head-mounted display Oculus Rift induces motion sickness and is sexist in its effects. Exp. Brain Res., 235 (2017) 889-901.

[61] O. Merhi, E. Faugloire, M., Flanagan, T.A. Stoffregen, Motion sickness, console video games, and head mounted displays, Hum. Factors 49 (2007) 920-934.

[62] B. Keshavarz, A.C. Novak, L.J. Hettinger, T.A. Stoffregen, J.L. Campos, Passive restraint reduces visually induced motion sickness in older adults, J. Exp. Psychol.: Appl. 23 (2017) 85-99.

[63] C.T. Bonnet, E, Faugloire, M.A. Riley, B.G. Bardy, T.A Stoffregen, Self-induced motion sickness and body movement during passive restraint. Ecological Psychology 20(2) (2008) 121-145.

[64] X. Dong, K. Yoshida, T.A. Stoffregen, Control of a virtual vehicle influences postural activity and motion sickness, Journal of Experimental Psychology: Applied 17 (2011) 128-138. 
[65] Y.C. Chen, X. Dong, F.C. Chen, T.A. Stoffregen, Control of a virtual avatar influences postural activity and motion sickness, Ecological Psychology 24 (2012) 279-99.

[66] A.M. Gavgani, K.V. Nesbitt, K.L. Blackmore, E. Nalivaiko, Profiling subjective symptoms and autonomic changes associated with cybersickness. Autonomic Neuroscience, 203 (2017) 41-50.

[67] P.A. Howarth, S.G. Hodder, Characteristics of habituation to motion in a virtual environment, Displays 29 (2008) 117-123.

[68] R.S. Kennedy, K.M. Stanney, W.P. Dunlap, Duration and exposure to virtual environments: sickness curves during and across sessions, Presence: Teleoperators \& Virtual Environments 9(5) (2000) 463-472.

[69] E.G. Regan, Some evidence of adaptation to immersion in virtual reality, Displays 16 (3) (1995) 135-139.

[70] J. Heutink, M. Broekman, K.A. Brookhuis, B.J.M. Melis-Dankers, C. Cordes, The effects of habituation and adding a rest-frame on experienced simulator sickness in an advanced mobility scooter driving simulator, Ergonomics, (2018) 1-11. DOI: $10.1080 / 00140139.2018 .1518543$

[71] R.S. Kennedy, N.E. Lane, K.S. Berbaum, M.G. Lilienthal, Simulator sickness questionnaire: An enhanced method for quantifying simulator sickness, Int. J. Aviat. Psychol. 3 (1993) 203-220.

[72] B. Keshavarz, H. Hecht, Validating an efficient method to quantify motion sickness, Human factors 53 (2011) 415-426.

[73] D. Lin, H. Seol, M.A. Nussbaum, M.L. Madigan, Reliability of COP-based postural sway measures and age-related differences, Gait \& posture 28(2) (2008) 337-342.

[74] R.F. Lorch, J.L. Myers, Regression analyses of repeated measures data in cognitive research, Journal of Experimental Psychology: Learning, Memory, and Cognition 16(1) (1990) 149-157.

[75] S. Palmisano, B. Arcioni, P.J. Stapley, Predicting vection and visually induced motion sickness based on spontaneous postural activity, Experimental brain research 236(1) (2018) 315-329.

[76] A.M. Hashemian, B.E. Riecke, B. E., Leaning-based 360 interfaces: investigating virtual reality navigation interfaces with leaning-based-translation and full-rotation, In: 
International Conference on Virtual, Augmented and Mixed Reality, Springer, Cham, 2017, pp. 15-32.

[77] W. Bles, J.E. Bos, B. De Graaf, E. Groen, A.H. Wertheim, Motion sickness: Only one provocative conflict? Brain Res. Bull. 47 (1998) 481-487. 